\title{
Structural evaluation of the DeepCWind offshore wind platform
}

\author{
Diogo Vasconcelos \\ Instituto Superior Técnico, Universidade de Lisboa, 1049-001 Lisboa, Portugal \\ diogo.vasconcelos@tecnico.ulisboa.pt
}

Mário Vieira

IDMEC, Instituto Superior Técnico, Universidade de Lisboa, 1049-001 Lisboa, Portugal

mario.vieira@ist.utl.pt

Diogo Dias

Instituto Superior Técnico, Universidade de Lisboa, 1049-001 Lisboa, Portugal

diogo.r.dias@tecnico.ulisboa.pt

\section{Luis Reis}

IDMEC, Instituto Superior Técnico, Universidade de Lisboa, 1049-001 Lisboa, Portugal luis.g.reis@tecnico.ulisboa.pt, bttp:/ / orcid.org/0000-0001-9848-9569

\begin{abstract}
Wind power technologies are being used as a mean of harvesting the energy from the wind with low carbon impact and with great potential to contribute to a new energy paradigm. Great benefits may arise from the use of offshore turbines, such as having a reduced visual impact, if far enough from the coast, or being able to produce more energy due to the use of bigger turbines. Current challenges for these technologies include producing a stable and profitable platform that allow turbines to be installed in deep waters, meaning that these solutions need to be of floating type. An example of such structure is the foundation developed by the DeepCWind consortium, which is evaluated for its structural integrity on this document. The evaluation consists of modal and static/transient analyses, according to a selected Design Loading Case, which is defined for the certification of wind turbines' offshore foundations. The objective is to observe how this structure would perform when subjected to a simulated real life loading. The DeepCWind foundation exhibited great difficulties enduring the applied loads. Therefore, the structure was reinforced in order to safely undergo the required design loading case.
\end{abstract}

KEYwORDS. Wind energy; Offshore wind; DeepCWind; Offshore foundations.

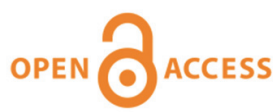

Citation: Vasconcelos, D., Vieira, M., Dias, D., Reis, L., Structural Evaluation of the DeepCWind Offshore Wind Foundation, Frattura ed Integrità Strutturale, 51 (2020) 2444.

Received: 17.07.2019

Accepted: 11.09.2019

Published: 01.01.2020

Copyright: (C) 2020 This is an open access article under the terms of the CC-BY 4.0, which permits unrestricted use, distribution, and reproduction in any medium, provided the original author and source are credited. 


\section{INTRODUCTION}

he recent move towards electrical transportation, the development of other economies, as well as the emergence of a digitalized world, will increase the need for electricity production. It is estimated that it could lead to a $90 \%$ rise in power demand from 2018 to 2040 [1].

On the other hand, the Paris Climate Agreement was signed. This agreement results from an international effort to strengthen the global response to the threat of climate change and to intensify the actions that have to be taken for a sustainable low carbon future. The main goal of the agreement is to promote a sustainable development by keeping a global average temperature rise well below 2 degree Celsius above pre-industrial levels, throughout this century. Furthermore, a limit of 1.5 degrees should be pursued [2]. For that reason, the use of renewable energy sources is of major importance. One of the most significant sources is the wind, which Mankind has been using for its needs for centuries.

Nowadays, the sight of wind turbines on land is very common but the prospective trend is the emergence of offshore wind turbines. Although offshore wind capital costs are still higher than those of other renewable technologies, a decline has been registered since 2015 [3]. For Europe, offshore wind power may be a key player for further energy production capacity, as it has at its disposal a large marine space with strong wind potential [4]. At the end of 2018, Europe's cumulative installed offshore wind capacity was 18499 MW, with 2649 MW being added to the grid in the referred year [5]. At offshore sites, the wind presents less turbulent conditions, due to the lack of obstacles, which is a major advantage for a steady electricity production. Another key advantage is the possibility of using bigger turbines and thus producing more power. The use of bigger turbines is more advantageous at sea due to eased transportation logistics, reduced land used and less visual/wildlife impacts [6]. However, offshore structures are subjected to severe dynamic loads due to wind, waves, currents and mechanical loads [7].

After going from onshore to offshore wind power, the next big step is going from bottom-fixed platforms into the floating type, which are for use in deep waters (more than 60 meters). This is a step which may lead to great benefits as most of the potential of the offshore wind resource is in waters with depths that are too deep for the installation of an economically competitive bottom-fixed foundation [8].

An example of a floating platform is the DeepCWind. The DeepCWind structure was developed by the DeepCWind consortium $^{1}$ as an initiative to support the research on floating offshore wind technologies [9]. It was used by the Offshore Code Comparison Collaboration Continuation (OC4) as a way to generate test data for validation of offshore wind turbine modeling tools. The results of the experiment allow for a better understanding of offshore floating wind turbine dynamics and modeling techniques, as well as a better awareness of the validity of various approximations [10]. This structure is still under development and no real scale model has been produced. Nonetheless, a 1:50 scale model was used in 2013 for tank testing. The DeepCWind foundation was designed to support the NREL 5 MW Reference Wind Turbine [11].

To perform a structural analysis, the Finite Element Method (FEM) was used. The FEM is a numerical analysis technique that produces approximate solutions for engineering problems. It examines a domain of interest by discretizing it into an assembly of finite elements. Partial differential equations are then used to find an approximate solution, within each element, for how the structure behaves when subjected to certain loads or excitations [12]. The ANSYS software was used to perform the FEM analysis.

With the purpose of verifying the suitability of an offshore structure, several design load cases (DLC) are made available. This document uses DLCs defined on a standard published by Germanischer Lloyd (GL) [13]. Different types of finite element analysis were performed and are presented in the following sections.

It should me mentioned that the DeepCWind Program did not take any real part in defining or validating the structural integrity of the platform. As such, this paper credits no responsibility to them regarding the conclusions on structural integrity.

\section{METHODS}

Project Approach

he approach of this project was divided in two stages. Initially, the original DeepCWind design was computationally evaluated at the DLC 1.1 conditions (briefly explained in later sections). Firstly, static structural analyses were performed at $11.4 \mathrm{~m} \mathrm{~s}^{-1}$ and it was verified that the structure was unable to cope with the applied stresses. Secondly,

\footnotetext{
${ }^{1}$ The DeepCWind consortium is a group of universities, national labs and companies, which are funded by the USA Department of Energy.
} 
the structure was structurally reinforced, in order to improve its response to the applied loads. Finally, the improved design was tested in transient analyses at $11.4 \mathrm{~m} \mathrm{~s}^{-1}$ and $24 \mathrm{~m} \mathrm{~s}^{-1}$. This project does not yet include a fatigue damage evaluation. However, in following work, this evaluation should be performed, as this structure are subjected to fatigue damage accumulation, due to variable cyclic loading, thus resulting in the appearance of fatigue cracks that lead to the reduction of the structure service life [14].

\section{Tower and Turbine Properties}

A Wind Turbine consists of several parts, namely: the blades, the tower, the hub (where the blades are connected) and the nacelle (which stands on top of the tower and supports the hub). The nacelle contains the generator and the gearbox. As stated before, the turbine used within this research is the NREL 5 MW Reference Turbine. Tab. 1 displays its most relevant properties:

\begin{tabular}{cc}
\hline Hub Height above SWL & \\
Hub Mass & $90 \mathrm{~m}$ \\
Nacelle Mass & $56780 \mathrm{~kg}$ \\
Tower Height & $75000 \mathrm{~kg}$ \\
Tower Height above SWL & $87.6 \mathrm{~m}$ \\
Tower Mass & $347460 \mathrm{~kg}$ \\
Rotor Diameter & $126 \mathrm{~m}$ \\
Blade Length & $61.5 \mathrm{~m}$ \\
Blade Mass & $17740 \mathrm{~kg}$ \\
Cut-In Wind Speed & $3 \mathrm{~m} / \mathrm{s}$ \\
Rated Wind Speed & $11.4 \mathrm{~m} / \mathrm{s}$ \\
Cut-Out Wind Speed & $25 \mathrm{~m} / \mathrm{s}$ \\
\hline
\end{tabular}

Table 1: NREL 5 MW Reference Turbine Properties [7].

\section{DeepCWind Foundation}

The original model is made of circular section members only. The following pictures show the overall dimensions of the foundation. The members are identified as MC (main column), UC (upper columns) and BC (bottom columns). The tubular thin walled members that make the connections between each columns are identified as DU (delta upper pontoon), DL

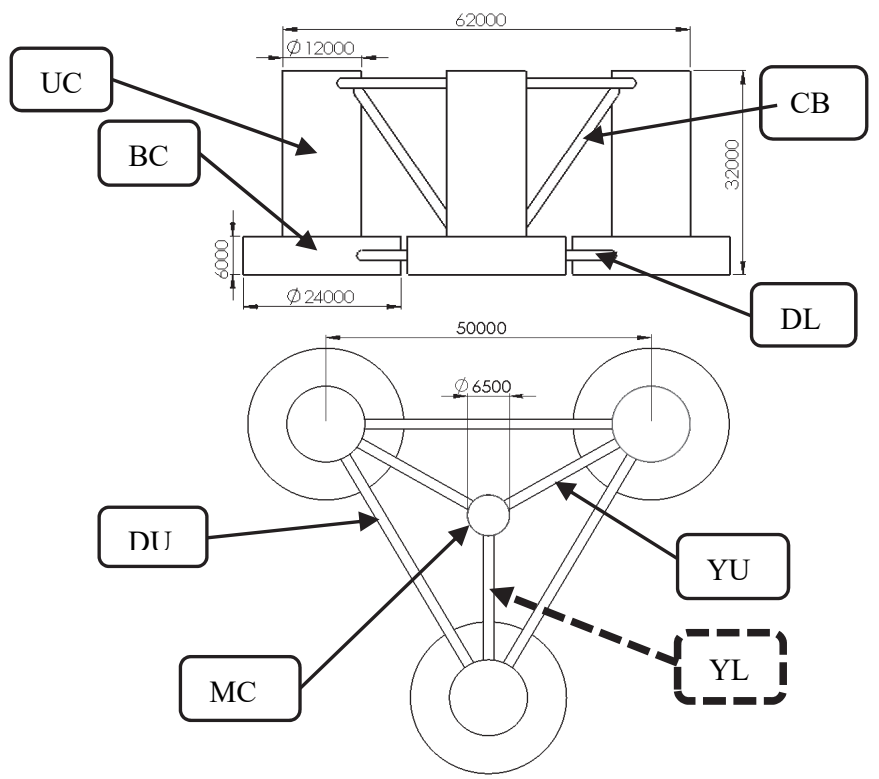

Figure 1: Dimensions of the DeepCWind Platform; adapted from [6]. YL member is hidden.

\footnotetext{
2 Sea Water Level
} 
(delta lower pontoon), YU (Y upper pontoon), YL (Y lower pontoon) and CB (cross brace). Additionally, they may also be referred as Pontoons. In order to fully comprehend the structure geometry, Fig. 1 shows the referred geometry, as well as the most important dimensions of the platform.

The BC columns will also act as heave plates. For further stability, the BC and UC columns are filled with a certain amount of water, which will perform as a ballast tank. Tab. 2 shows data on each member thickness and Tab. 3 displays general information on the foundation.

\begin{tabular}{ll}
\hline Member & Thickness \\
UC & $60 \mathrm{~mm}$ \\
BC & $60 \mathrm{~mm}$ \\
MC & $30 \mathrm{~mm}$ \\
Pontoons & $17.5 \mathrm{~mm}$ \\
\hline
\end{tabular}

Table 2: Member Thicknesses [6].

\begin{tabular}{ll}
\hline Platform mass, including ballast & 13473 Tonnes \\
Platform Mass & 3852 Tonnes \\
Depth of Platform below SWL & $20 \mathrm{~m}$ \\
Max Elevation of Platform above SWL & $12 \mathrm{~m}$ \\
\hline
\end{tabular}

Table 3: Foundation General Information [6].

The platform total mass, including the steel structure and the water ballast, was projected to ensure that the combined weight of the tower(including the rotor-nacelle assembly) and of the floating platform, will balance with buoyancy force of the undisplaced platform in still water. The centre of mass of the floating platform alone is located at $13.46 \mathrm{~m}$ along the platform centreline below the SWL [8]. In future improvements of the structure, the total mass should be conserved. This means that if the mass of the structure increases, an equivalent decrease within the mass of water (ballast) should be made. At the current state, the three upper columns are filled with water from the bottom up to $6.17 \mathrm{~m}$ below the SWL, and the base columns are filled from draft to $5.11 \mathrm{~m}$ above draft [10].

As for the properties of the Steel used - namely, S355 steel was selected - the Young Modulus is 210 GPa and the Shear Modulus is $77 \mathrm{GPa}$, as suggested by document [10]. For the density, the usual value for structural steel is around 7850 $\mathrm{kg} / \mathrm{m}^{3}$, but it was changed to $8500 \mathrm{~kg} / \mathrm{m}^{3}$, in order to account for paint, bolts, welds and flanges, as suggested in the DeepCWind OC4 technical report [10]. At the cross-sections, a radius of concordance was considered, being defined as equal to the thickness of the thinnest member, as suggested by the standard [15].

The platform is anchored to the ocean floor by three catenary lines which have a $120^{\circ}$ angle between them, to prevent the dislocation of the platform during operation. The mooring lines attach to the platform at a depth of $14 \mathrm{~m}$ below the SWL and at a radius of $40.87 \mathrm{~m}$ from the platform centreline. The other end of the mooring line is connected to the ocean floor at a water depth of $200 \mathrm{~m}$ below the SWL and at a radius of $837.6 \mathrm{~m}$ from the platform centreline. Each mooring line has $835.5 \mathrm{~m}$ in length when not stretched [10].

\section{FAST Model Definition}

Offshore structures are subjected to hydrostatic, hydrodynamic and aerodynamic loadings, usually due to the wind, waves and tides. In order to produce the correct inputs to use as loads on the Finite Element Analysis, the FAST code from NREL was used. FAST stands for Fatigue, Aerodynamics, Structures and Turbulence. This software is an aeroelastic simulator capable of calculating loads on two or three bladed horizontal-axis wind turbines [16]. The structure being analysed is specified within the program, as well as the sea and weather conditions that are desired. The DeepCWind is one of the several Certification Tests that comes integrated with the software. As such, the FAST simulation was developed using the $25^{\text {th }}$ Certification Test as a basis and making changes according to the existing needs. This software works as an assembly of independent modules, being each part responsible for a certain aspect of the simulation, like the hydrodynamic loads or the wind behaviour.

One of the key aspects of the simulation is the behaviour of the sea, as it is responsible for the most destructive loads applied on the structure. The sea waves can be simplified by assuming that their behaviour is similar to a sinusoidal wave, thus regular wave theory may be applied. 
The waves are usually random in their heights, wave lengths and periods. For this reason, its behaviour has to be described in a probabilistic way. Several quantities may be used to describe it stochastically, being the most important the Significant Wave Height and the Peak Wave Period. The Significant Wave Height, $\mathrm{H}_{\mathrm{s}}$, is the mean of the highest third of the waves in a time-series that represents a certain sea state. The Peak Wave Period, $\mathrm{T}_{\mathrm{p}}$, is the wave period with the highest energy [15]. Fig. 2 displays an idealization of a certain sea state.

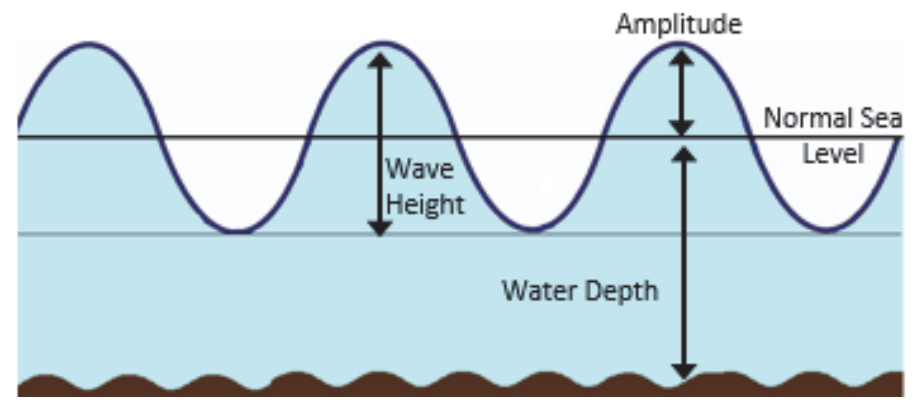

Figure 2: Idealized Sea State.

For this research, a real specific location had to be chosen, in order to use accurate data of weather conditions. For the NREL's study, the location used was $61^{\circ} 20^{\prime} \mathrm{N}$ latitude and $0^{\circ} 0^{\prime} \mathrm{E}$ longitude. For the present document, the same choice was made. This location is at the northeast of the Scottish Shetland Islands and it was chosen due to its extreme wind and wave conditions, which would allow the structure to be used at locations that combine extreme weather conditions and high sea depths. After a review of the environment at this site, the following external conditions were considered:

- Wind mean speed of $11.4 \mathrm{~m} \mathrm{~s}-1$; Hs: $2.466 \mathrm{~m}$; $\mathrm{T}_{\mathrm{p}}$ : $13.159 \mathrm{~s}$;

- Wind mean speed of $24 \mathrm{~m} \mathrm{~s}-1$; Hs: $5.896 \mathrm{~m}$; $\mathrm{T}_{\mathrm{p}}$ : $19.266 \mathrm{~s}$.

The wind speed is considered at hub height. The value of $11.4 \mathrm{~m} \mathrm{~s}^{-1}$ was selected because it is the rated speed of the $5 \mathrm{MW}$ Reference Turbine [11]. The rated speed is the wind velocity at which the turbine starts to produce energy at its nominal power.

With the intention of calculating the hydrodynamic loads on the structure, three options can be used: potential-flow theory, strip-theory or a combination of both. The potential-flow theory can be used to substructures or members of substructures that are large relatively to a typical wavelength. It includes linear hydrostatic restoring, the added mass and damping contributions from linear wave radiation and the incident-wave excitation [17]. The strip-theory solution is usually desirable for substructure or members of substructures that are small in diameters relatively to a typical wavelength. The loads can be applied across multiple interconnected members. The relative form of Morison's equation is used. This theory can include ballasting of members and the effects of marine growth. When there is flow separation, viscous-drag forces become dominant and this formulation is preferable. Morison's equation is favoured for severe wave conditions. Therefore, as these conditions are believed to be the most critical for this specific analysis, the Morison's equation was used [18].

In order to recreate the irregular behaviour of the waves, a frequency based density spectrum is used, which is based on a probabilistic approach. The suggested spectrums, by the GL standard [13], are the Pierson-Moskowitz or the JONSWAP. The difference between both of them relies on the development state of the sea. If the energy transfer between the wind and the sea reaches a point of balance, meaning that the energy of the wave remains constants, it is said that the sea is in a fully developed sea state. The Pierson-Moskowitz spectrum considers fully developed sea state, whereas JONSWAP contemplates that the sea is never in a fully developed state, which means that the waves will continue to grow in height over the distance they cover [18].

The wave kinematics are modelled using the Airy wave theory applied to irregular waves. Irregular waves can be represented as a summation or superposition of multiple wave components. This theory also describes how the undisturbed fluidparticle velocities and accelerations decay exponentially with depth [17]. For this simulation, the Airy model with the PiersonMoskowitz spectral density was used. The Airy model is the unique available in FAST and the Pierson-Moskowitz was the one considered for the data analysis of the sea and wind conditions [18].

A Design Load Case is a combination of events or conditions that the structure may encounter and which need to be successfully evaluated in order to proceed to the certification of an Offshore Wind Turbine. The test being used throughout this research is DLC 1.1 by GL [13]. This test states that the turbine is producing energy while connected to the grid. The wind velocity should be between the cut-in wind speed and the cut-out wind speed. The cut-in speed is the lowest mean speed, at hub height, at which the turbine starts producing energy, $3 \mathrm{~m} / \mathrm{s}$. The cut-out speed is highest mean speed, at hub height, at which the turbine stops producing energy, $25 \mathrm{~m} / \mathrm{s}$. The test requires an analysis of at least 600 seconds. The partial 
load factors are described in the previously referred GL document. These factors relate to a safety coefficient meant to be factored into the applied loads, preventing possible inaccuracies in those loads. However, for this academic research, the partial load factors were not applied to the loads. Instead, they were used as guidance for a stress safety factor, which ought to be of at least 1.2 .

\section{Definition of the Structural Analyses \\ Modal Analysis}

When a structure moves or deforms rapidly, the understanding of its dynamic behaviour is critical. This behaviour can be computationally assessed through the structure's vibrations without external forces, also known as free vibrations [19]. From this simulation, we may acknowledge the natural frequencies of the structure and its deformation shapes. A natural frequency is a frequency at which the structure tends to vibrate, undergoing large displacements and stresses. If the frequency of the applied force coincides with one of the natural frequencies of the structure, this will lead to resonance. Thus, the designer should make sure that the natural frequencies of the structure do not overlap with the frequencies it can experience in real world, otherwise it may lead to catastrophic consequences [19].

In the case of the present structure, three major sources of excitation will be considered, which can lead to structural resonance:

- The rotor frequency;

- The passing of the blades frequency;

- The waves frequency.

The rotor frequency is the frequency of revolution of the rotor, also known as $1 P$, which may induce dynamic loads, for example due to rotor unbalances.

The passing of the blades frequency is the frequency at which the blades pass the tower, in this case, for a three-bladed turbine is also known as 3P.

The DNV states that a 10\% security factor should be used for the $1 \mathrm{P}$ and $3 \mathrm{P}$ frequencies [20].

The most destructive source of excitation is the frequency of the waves, which can be estimated using information on the most common wave conditions verified at a certain place, through a certain amount of time. By identifying the minimum and maximum frequencies verified, an interval was established, in which a natural frequency of the structure should not be present.

The 1P frequency interval can also be estimated. The 5 MW NREL Reference Turbine works from a minimum of $6.9 \mathrm{rpm}$ until a maximum of $12.1 \mathrm{rpm}$ [11]. This means that the $1 \mathrm{P}$ frequency interval goes from $\mathrm{f}_{1 \mathrm{P}, \min }=0.12 \mathrm{~Hz}$ to $\mathrm{f}_{1 \mathrm{P}, \max }=0.20 \mathrm{~Hz}$. Using the factor of $10 \%$, the interval is updated to go from $0.104 \mathrm{~Hz}$ to $0.22 \mathrm{~Hz}$. The $3 \mathrm{P}$ frequency is obtained through the multiplication of $1 \mathrm{P}$ for the number of blades present, obtaining an interval that goes from $\mathrm{f}_{3 \mathrm{P}, \min }=0.31 \mathrm{~Hz}$ to $\mathrm{f}_{3 \mathrm{P}, \text { max }}=0.67$ $\mathrm{Hz}$. The waves at the considered installation site will, most probably, vary from 6 to 20 seconds, meaning a frequency range from $0.05 \mathrm{~Hz}$ to $0.167 \mathrm{~Hz}$ [18]. The resulting ranges can be seen in Fig. 3.

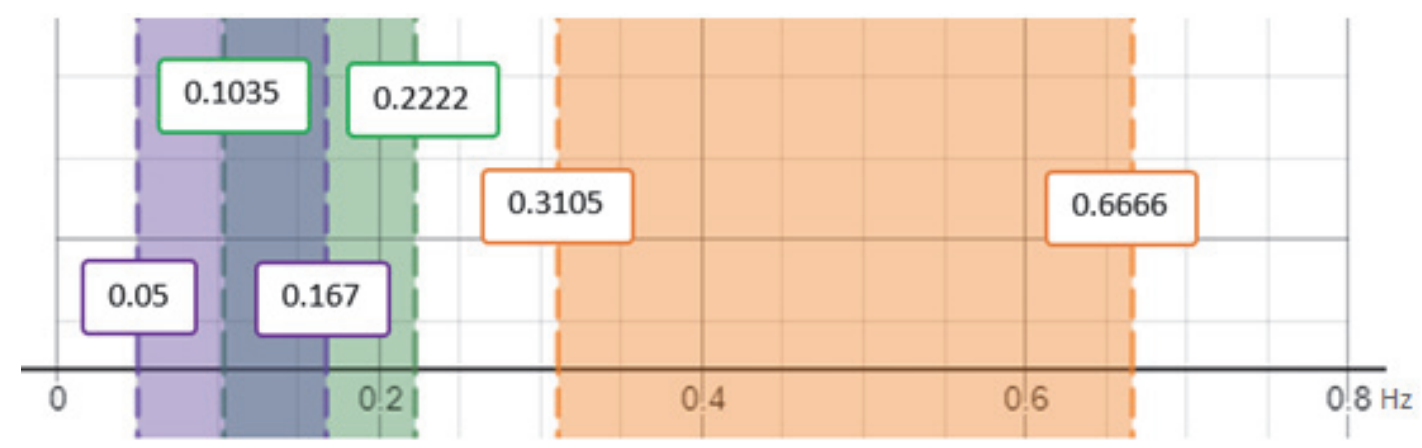

Figure 3: Resulting range from the application of most relevant sources of excitation.

Depending on where the fundamental frequency (the first bending natural frequency), $\mathrm{f}_{0}$, is located, the structure can be classified as:

- Soft-Soft: if the fundamental frequency is lower than the 1P frequency;

- Soft-Stiff: if the fundamental frequency is higher than the $1 \mathrm{P}$ frequency but lower than the 3P frequency;

- Stiff-Stiff: if the fundamental frequency is higher than the 3P frequency [21]. 


\section{Static and Transient Analysis}

Static structural analysis determines the response of the structure when subjected to loads that do not include significant inertia and damping effects. Thus, steady loading and response conditions are presumed, varying slowly with time [22]. In real situations, all loads vary with time. If the excitations applied to the structure vary considerably over time, a dynamic simulation should be done. To achieve this, a transient analysis ought to be performed.

According to the GL standard [13], the time of the simulation should be of 10 minutes. For this type of analysis, 10 minutes are seen as representative, due to the fact that they can represent what is called an environmental state. An environmental state is a set of brief environmental conditions of approximately constant intensity parameters, with a usual duration of 10 minutes or one hour [13].

In order to accurately represent these 10 minutes (600 seconds), a simulation of 1000 seconds was made with FAST. During the treatment of the FAST data, the first 200 seconds were ignored, as the initial conditions are not correct, as they reflect a computational transitory response to the imposed conditions. Then, 800 seconds are inserted into ANSYS, from which the first 200 seconds of the simulation will be ignored, due to the same referred reasons. As a result, the analysis will have the required 600 seconds.

Computer effort and time consumption is a key consideration when performing FEM analysis. For this reason, it is sensible to perform a static simulation previously to a transient one, which will be much more time consuming, as well as using more computational resources. Transient analysis are, usually, more damaging to the structure and thus should be performed if a static simulation yields results that show that the structure will not collapse under the considered loads. Otherwise, the static analysis should be enough to verify that the structure cannot endure the specified loads.

\section{Structural Analysis}

Structural analysis were performed, evaluating the platform, as well as the tower. The first analyses of the original platform were shell analyses. This type of analysis is extremely helpful, as it can accurately describe a thin model while at the same time it leading to huge computational time savings. This type of analysis is most appropriate when the $\mathrm{t} / \mathrm{L}$ coefficient is low (lower than 0.2), where $t$ is the thickness of the member and $\mathrm{L}$ is its length [23]. The maximum coefficient for the present structure is 0.01 , which more than satisfies the limit.

Despite being suitable, this first analysis did not consider the existence of a concordance radius on the structure joints, which resulted in localized high stresses at the joints of the elements. In order to correctly evaluate the stress concentration areas, a Submodel analysis was performed next. The Shell Model did not have fillet radius due to the fact that their generation (as surfaces) resulted in joints that did not accurately represent reality. Quadrilateral elements were used, Shell181.

As stated, the use of a Submodel Analysis was of major importance to accurately evaluate the stress at the member's joints. In this analysis, only a partial part of the model was evaluated. This partial model represented the joints and part of the members to ensure that all the important regions were evaluated. Solid tetrahedral elements were used, Solid187.

For the analyses of the reinforced structure, instead of performing separate evaluations, the type of mesh was changed to an hybrid shell-solid model. This model used shell elements for simple cylindrical areas, whereas solid elements were used at connection and segmentation zones. Fig. 4 shows the meshes used for the simple shell, solid submodel and hybrid shell+solid models.

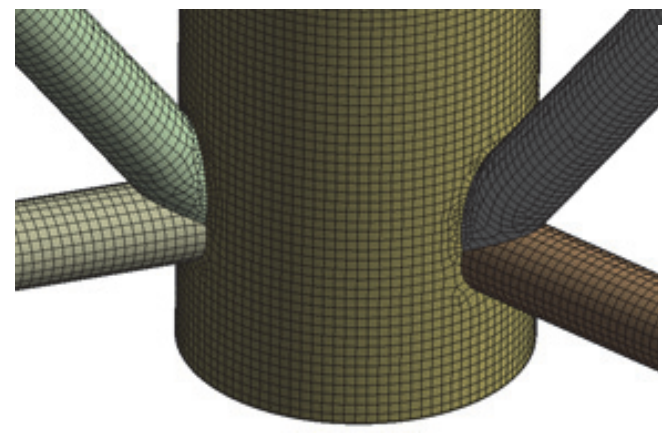

a)

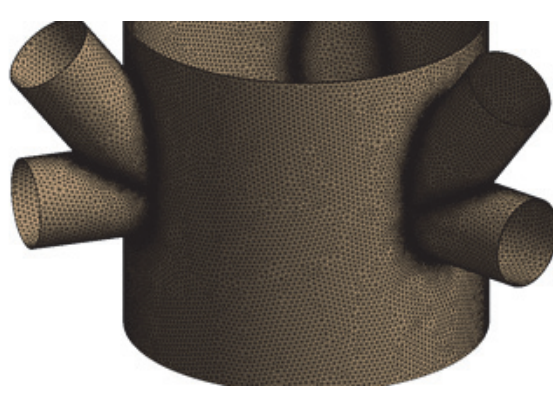

b)

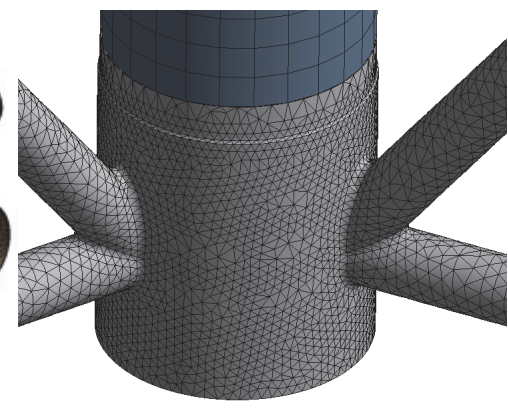

c)

Figure 4: a) Shell mesh; b) Solid Submodel mesh; c) Hybrid Shell + Solid Mesh

The simulation convergence is associated to how small the elements need to be to ensure that the results of the analysis are not affected by reducing the size of the mesh. More than one point should be considered and, as the mesh elements decrease in size, the stress should gradually converge to a particular value. If subsequent mesh refinements deliver approximately the 
same results, it is said that convergence has occurred [24]. For this research, a maximum of $10 \%$ change in the stress value is allowed to consider that the results have converged.

Additionally, and in order to control the quality of the mesh used, the Skewness metric was used. The Skewness determines how close to ideal a face or cell is [25]. This metric average value should be as low as possible, and its maximum, in perfect conditions, should be less than 0.95. Despite this, if a great amount of elements are used in the simulation, it will be difficult to have all the values below 0.95 and it is allowed to have a maximum above 0.95 (if the average is considerably below 0.95 ) [19].

\section{Boundary Conditions}

Boundary conditions are applied as constraints and loads to the analysed model. Generally, loads represent inputs to the model, such as forces, moments, pressures or temperatures. Constraints act as reactions to the applied loads, for instance imposing a fixed behaviour to a face of the model [24].

The loads applied to the present model include: hydrostatic pressure, forces (caused by the mooring lines), buoyancy forces, ballast pressure and dynamic pressures. Further information on these loads can be consulted in the following Master thesis [18].For the constraints, two approaches were used, in order to guarantee the validity of the results. The first approach was to use the displacements of the Tower (given by FAST), which are considered the true displacements of the structure but can maximize tensions near the connection tower-platform, where displacements are numerically defined. Thus, this approach is considered valid for members far away from this connection but should be seen with caution for the vicinities of the referred connection.

The second approach was based on the dynamic offset of the floating platform. As previously described, the platform is connected to the sea floor by the use of mooring lines in catenary form. This means that the structure can have a dynamic offset, as shown in Fig. 5, due to the applied loads. To simulate the behavior of mooring lines, the ANSYS software allows the use of springs, even though this model has some limitations for reproducing the catenary behavior [26]. Typical chain mooring lines, can have an axial stiffness of around $7.1 \times 10^{8} \mathrm{~N}$, when divided in 8 segments with a combined length of, approximately, $500 \mathrm{~m}$ [27]. As previously presented, the FAST software already had an implementation of the DeepCWind structure as a certification test, each with an EA coefficient of $7.54 \times 10^{8} \mathrm{~N}$. The axial stiffness of the mooring line will be lower, with a spring constant of $9 \mathrm{E} 5 \mathrm{~N} / \mathrm{m}$. To yield reliable results, when using linear springs, vessel displacements should be kept small [28], as this will also prevent rigid body motions [24]. Due to this, and also to guarantee that the applied forces are at least higher than the real ones, an axial stiffness of $1 \times 10^{8} \mathrm{~N}$ was used for the computational spring.

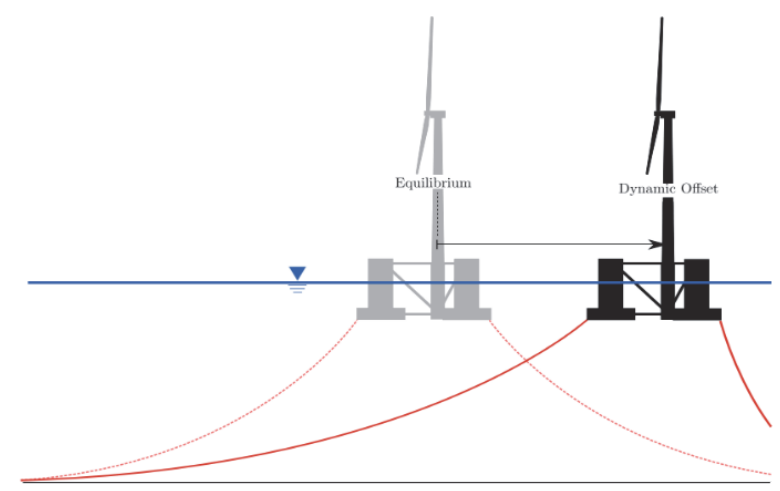

Figure 5 Dynamic Offset in response to loading conditions [23].

The disadvantage of this formulation is that it produces fictitious forces where the springs are connected to the model. It was decided to use both formulations presented above - displacement-based and spring-based, as complementary. The spring's formulation gives the most realistic results but to analyse the $\mathrm{BC}$ members, the displacement's formulation should be considered, to overcome the fictitious forces created by the springs.

\section{Linear Analysis}

The main objective of this analysis is to check if the structure can endure the applied loads. If the structure can sustain the loads, the constituting materials will remain in the elastic domain. In this case, a linear analysis is suitable and should produce valid results. On the other hand, if the structure can not undergo the applied loads, its material will go into plasticity. In this case, the linear analysis will not produce valid results. Linear analysis considers the absence of large deformation and in 
plasticity large deformation occurs. For this study, as the main objective is to check the structural integrity of the platform, if the structure enters plasticity it will be known that it can not endure the applied loads and the objective of this examination is achieved. As such, linear analysis were used as they require less computational resources. The plastic domain might present unrealistic deformations and the stresses should only be considered as an approximation. For further detail in the plastic behaviour of the platform, non-linear analysis should be performed with the appropriate plastic properties of the constitutive materials.

\section{RESULTS AND DISCUSSION}

s previously said, firstly the results of the analyses of the original platform will be discussed. Afterwards, the results
of the analyses of the structurally improved platform are discussed and comparisons made.

\section{Original Platform}

Modal Analysis Results

Since this research focuses on the behaviour of the foundation, the natural frequencies of the blades are of no interest. For simplification, the blades are omitted from the geometry and idealized with the inclusion of their masses at the combined centre of mass. In order to get results closer to the reality, a point mass was used instead. A point mass is an idealization which allows for the addition of inertial effects from a mass that in reality is present at the structure but is conceptualized in the simulation [29].

In addition, the presence of ballasts in the structure was also simulated with the use of point masses at their respective centres of mass. This simulation had around 31500 elements. The Skewness average value was 0.1159 . Therefore, the selected mesh is expected to have a good behaviour.

Fig. 6 shows the results of the modal analysis performed and the deformation shapes for Mode 1 (Side-to-Side and ForeAft) and Mode 2 (Side-to-Side, Fore-Aft and Torsion).

Tab. 4 shows the values of the relevant natural frequencies of the structure.

\begin{tabular}{ll}
\hline Mode Description & Frequency $[\mathrm{Hz}]$ \\
Mode 1 - Side-to-Side & 0.278 \\
Mode 1 - Fore-Aft & 0.279 \\
Mode 2 - Side-to-Side & 0.535 \\
Mode 2 - Fore-Aft & 0.537 \\
Mode 2 - Torsion & 0.546 \\
\hline
\end{tabular}

Table 4: Mode Description and respective Frequencies.

The fundamental frequency is $0.278 \mathrm{~Hz}$. One of the most important aspects to retain from Tab. 2 is that the fundamental frequency does not coincide with the real working frequencies that the structure is most probable to find in the real world. With this result, it can be stated that the structure's fundamental frequency is in the interval that goes from $0.22 \mathrm{~Hz}$ to 0.31 Hz. Being so, the structure can be classified as Soft-Stiff.

\section{Static Shell Simulation - Displacement Formulation}

The considered yield strength for structural steel is $355 \mathrm{MPa}$. The point masses previously referred were also included in all the static analysis.

This simulation used around 270000 elements. The Skewness maximum value was 0.9997 but its average value was $4.22 \mathrm{x}$ $10^{-2}$. Therefore, the selected mesh is expected to have a good behaviour.

Fig. 7 shows the overall result of the shell analysis, using the displacement formulation. 


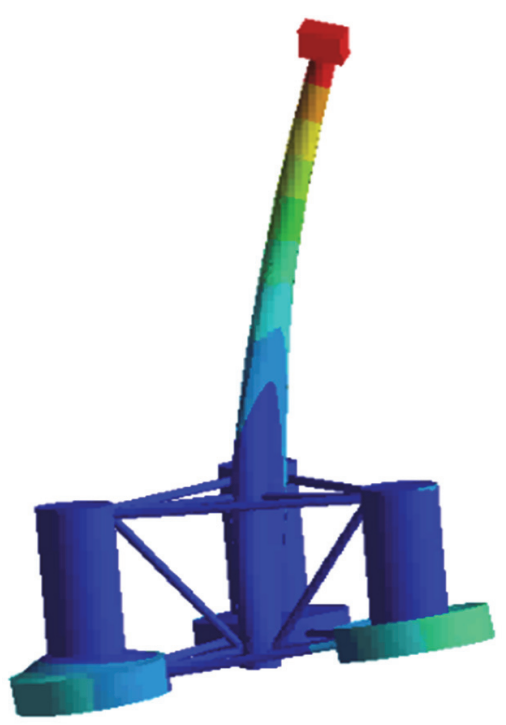

a)

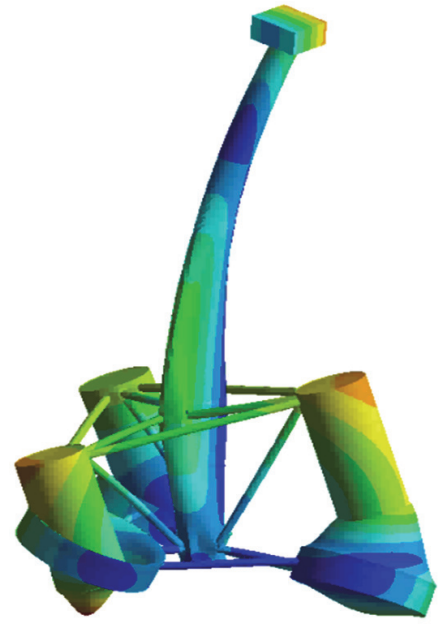

c)

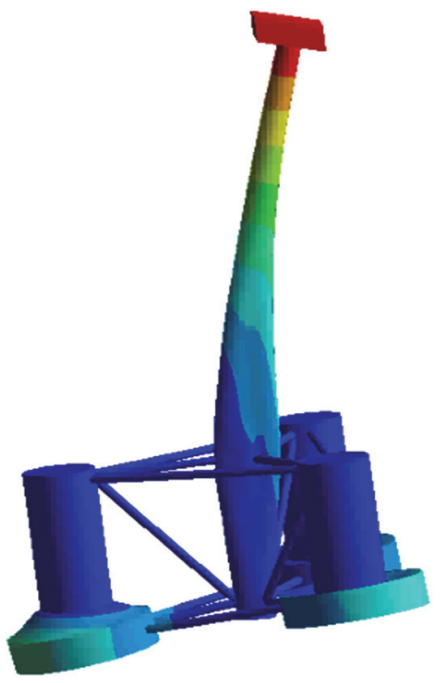

b)

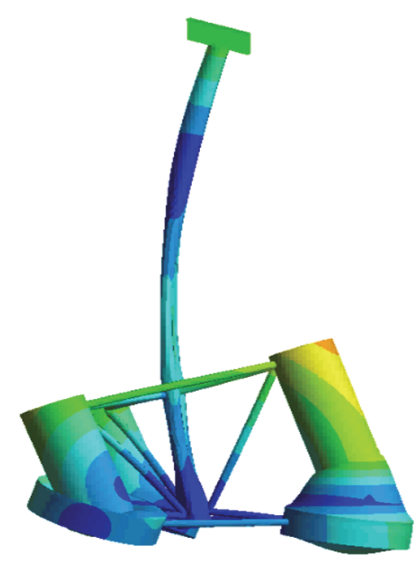

d)

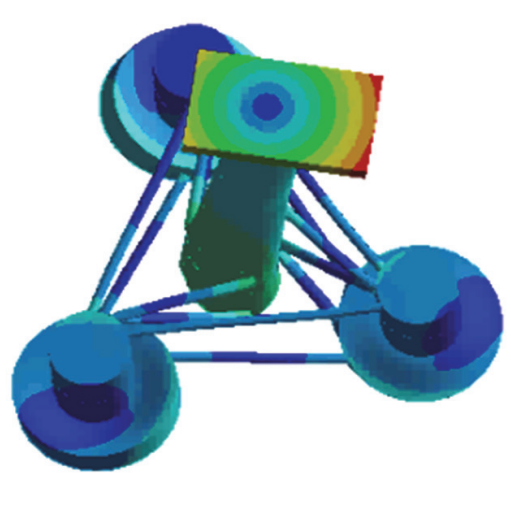

e)

Figure 6: Deformation Shapes from the Modal Analysis; a) Mode 1 - Side to Side; b) Mode 1 - Fore-Aft; c) Mode 2 - Side-to-Side; d) Mode 2 - Fore-Aft; e) Mode 2 - Torsion.

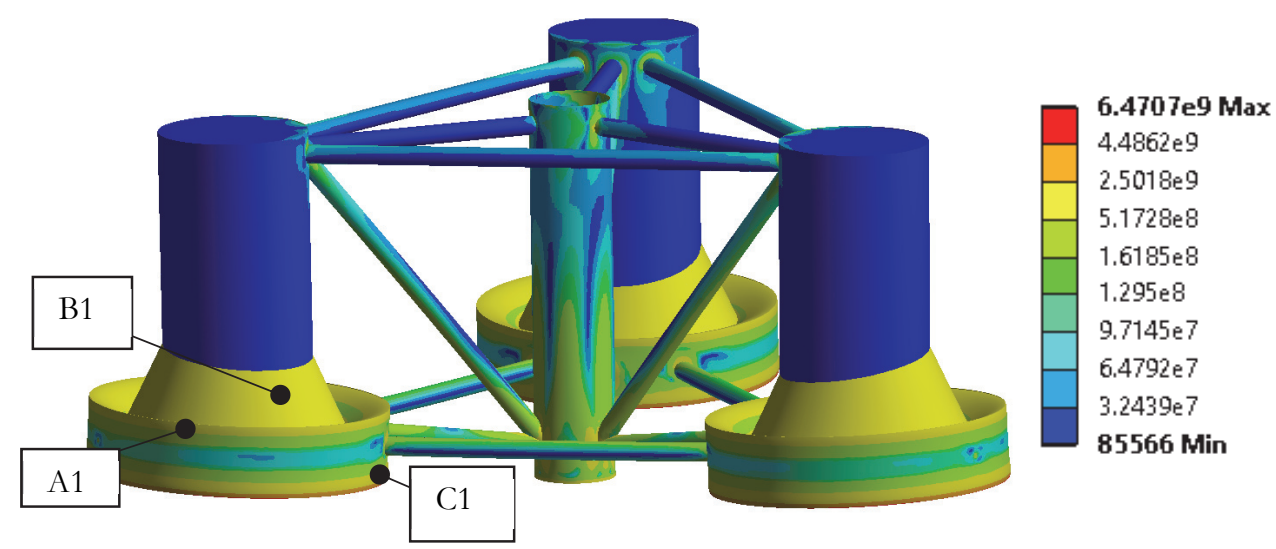

Figure 7: Results of the Shell Analysis, with the displacement formulation. 
From the observation of this Figure, there are three locations that stand out as critical:

- The joints where the Pontoons connect to the larger diameter elements;

- The Bottom Columns which are deformed by the normal stresses acting on their top and bottom surfaces.

- The Main Columns, which also present major difficulty enduring the loads.

As discussed in the previous section, the analysis with the displacements formulation should be specially used to analyse the $\mathrm{BC}$ members. As such, three points were selected, having the following magnitudes:

- A1: $1362 \mathrm{MPa}$

- B1: $1713 \mathrm{MPa}$

- $\mathrm{C} 1: 874.5 \mathrm{MPa}$

The $\mathrm{BC}$ column could not sustain the normal stresses on its top and bottom faces which causes them to deform in the represented manner. Inner supports should be considered in order to prevent this distortion.

The shell analysis is appropriate for this case, as it allowed for a relatively quick simulation with results which provide for an understanding of the structure behaviour. From this simulation, it is already possible to acknowledge that the structure is not suitable for operation as it is dimensioned, using the von Mises criteria. Despite this conclusion, a Submodel analysis was performed next, in order to get a more reliable simulation at the stress concentration regions.

\section{Submodel Analysis - Displacement Formulation}

The Submodel analysis allows the use of solid elements in combination with a faster simulation relatively to a full solid model simulation. For this simulation, the joints between Pontoons and larger diameter members were of concern. Fig. 8 shows a submodel of one of the BC members.

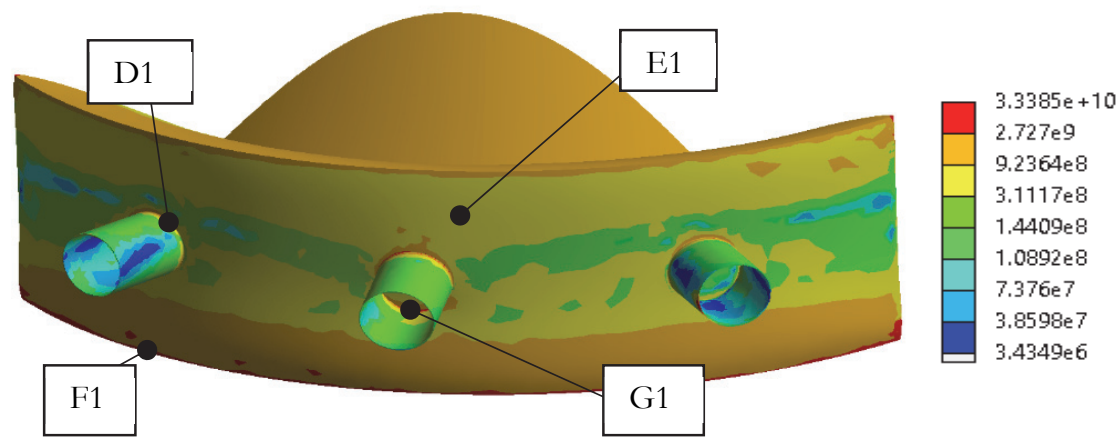

Figure 8: Submodel of the BC member.

From this submodel, it can be seen that the deformations and stresses are compatible with the previous results from the Shell analysis. The maximum stress is in the order of $10^{10}$ but this is due to the presence of singularities. A singularity is a point where some results of the solution do not converge. This happens when a certain load is applied to a corner or edge that is perfectly sharp (in the real world, there are seldom perfectly sharp edges) Furthermore the use of connections may also produce singularities. The imported displacements from the Shell analysis are directly applied as boundary conditions, in the Submodel analysis, on faces that in the real world possess no discontinuities [21]. These fictional high stress areas are then ignored. The considered high concentration areas are located in the joints of the elements and the four points highlighted present the following magnitudes:

- D1: $1450 \mathrm{MPa}$

- E1: $734 \mathrm{MPa}$

- F1: $3620.9 \mathrm{MPa}$

- $\mathrm{G} 1: 3728.1 \mathrm{MPa}$

The results of a solid model are more realistic than those of a shell model, thus its results are more accurate [30]. It is evident from the comparison of the results with the tensile load of the steel (355 MPa) that the structure cannot withstand the required conditions. 
Static Shell Simulation - Springs Formulation

As previously discussed, a spring formulation was also used to evaluate the structure. The objective of this analysis is to ensure that the structure is correctly constrained, by using two different methods. This model also represents the real situation more accurately. It is worth reminding that the springs used generate fictitious stress at the $\mathrm{BC}$ members. These members were more carefully examined in the previous section, using the displacements formulation. Fig. 9 shows the result of this analysis, with a shell model. It is worth mentioning that the use of a different boundary condition formulation allows to understand if the previous formulation generated fictitious stresses.
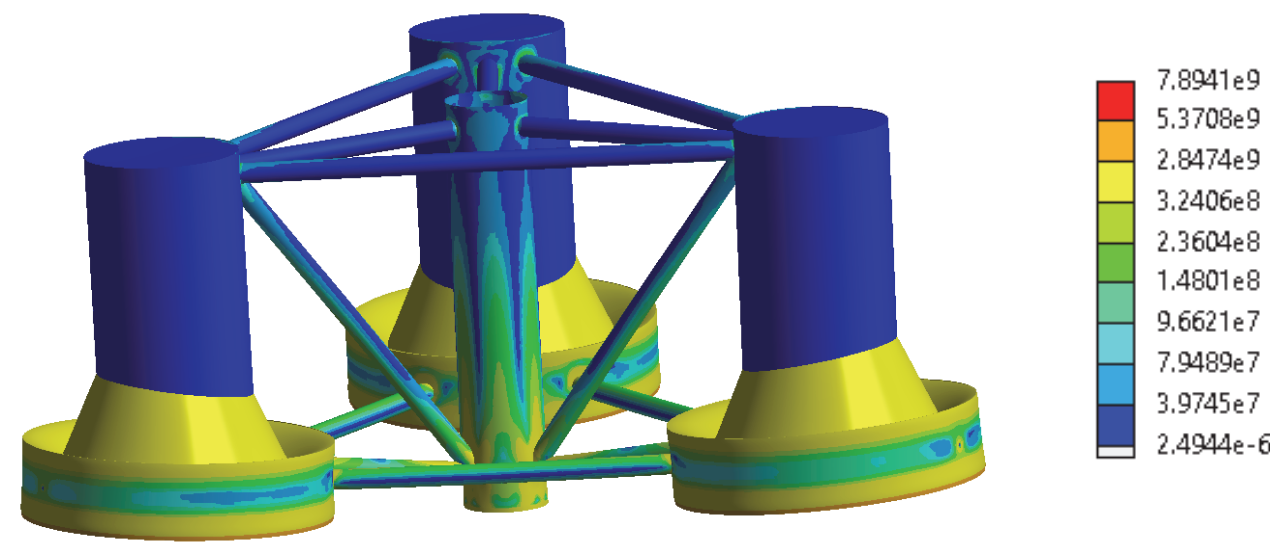

Figure 9: Shell analysis, with the Springs Formulation.

From the examination of Fig. 9, it can be understood that both analysis formulations give similar levels of stresses and comparable deformations. Fig. 10 shows two details of this analysis. At the left corner of this Figure, both details are situated in the global model.

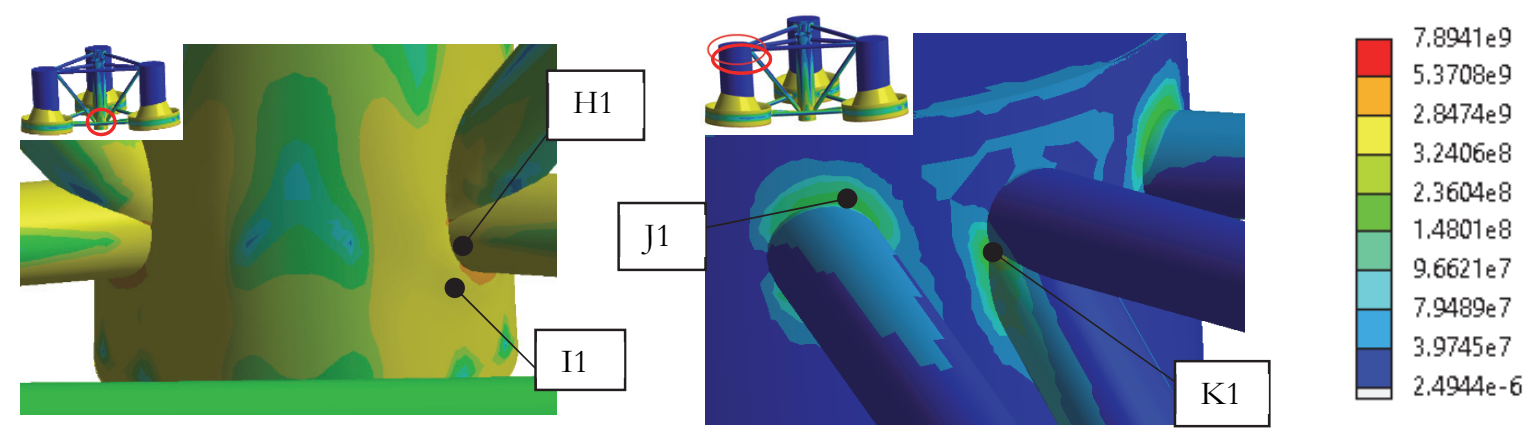

Figure 10: Details of the Shell analysis, using the Springs Formulation. At the left, the bottom of the MC column. At the right, the top of the UC.

Four points of interest were selected, having, respectively, the following magnitudes:

- H1: $652 \mathrm{MPa}$

- I1: $2170 \mathrm{MPa}$

- J1: $173 \mathrm{MPa}$

- K1: $391.63 \mathrm{MPa}$

\section{Submodel Analysis - Springs Formulation}

The Submodel analysis will, once again, confirm the shell results, by using reduced solid models of the areas with higher stress concentrations. The UC members, MC members, pontoons and joints were of concern for this analysis. Fig. 11 and 12 show the submodels with the greatest importance.

The highlighted points have the following magnitudes:

- L1: $294 \mathrm{MPa}$ 
- $\quad \mathrm{M} 1: 45.3 \mathrm{MPa}$

- $\quad \mathrm{N} 1: 336.7 \mathrm{MPa}$

- O1: $389.5 \mathrm{MPa}$

- P1: $450.4 \mathrm{MPa}$

- Q1: $327 \mathrm{MPa}$

- $\quad$ R1: $716.7 \mathrm{MPa}$

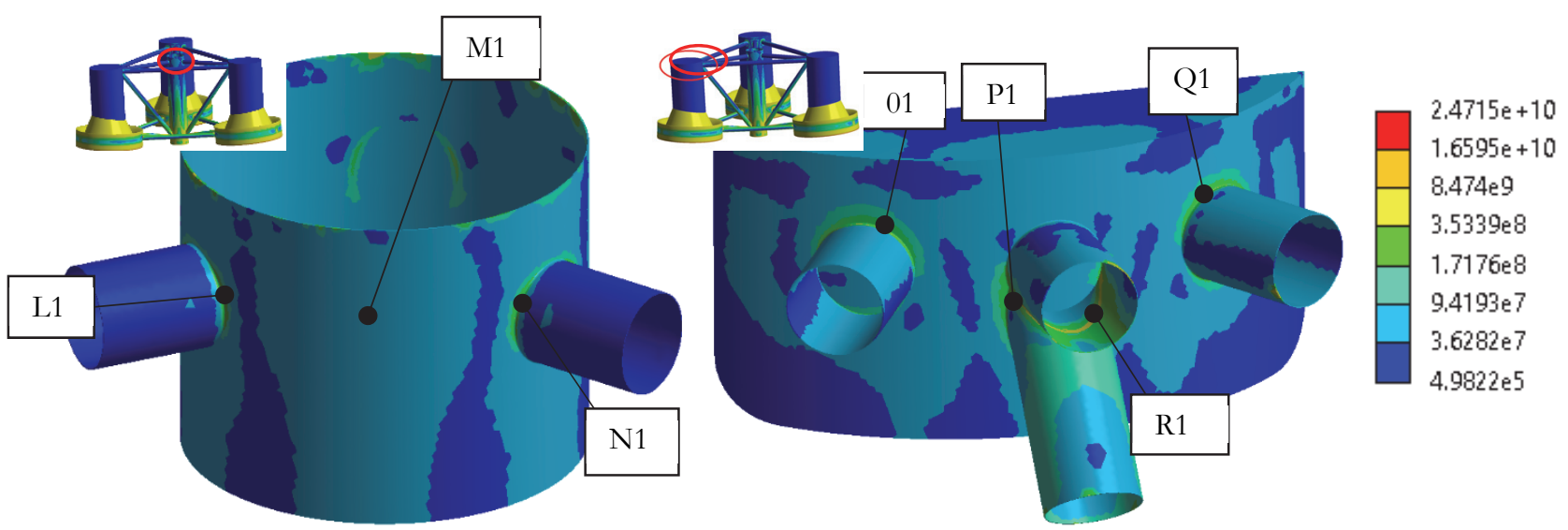

Figure 11: Submodels, using the Springs Formulation. At the left, the top of the MC column. At the right, the top of the UC.

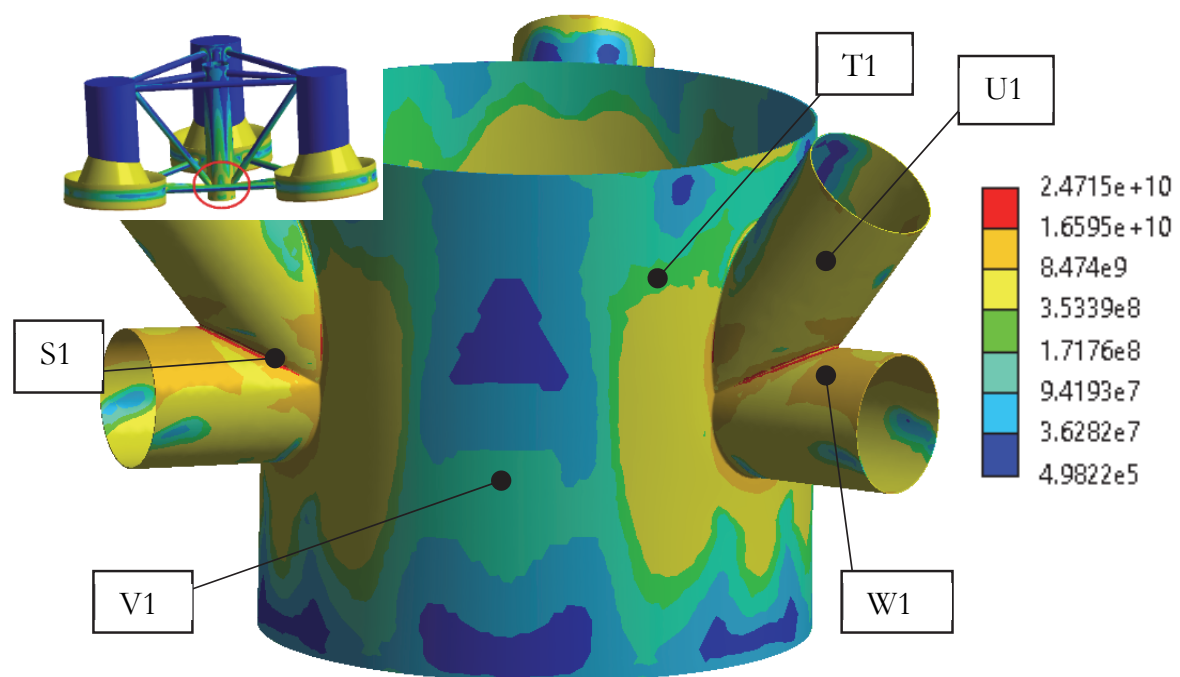

Figure 12: Submodel, using the Springs Formulation, of the bottom of the MC column.

Fig. 12 confirms that the higher stresses are located at the bottom of the MC column. The highlighted points have the following magnitudes:

- S1: $14061 \mathrm{MPa}$

- T1: $565.26 \mathrm{MPa}$

- U1: $2373 \mathrm{MPa}$

- V1: $376.87 \mathrm{MPa}$

- W1: $4141 \mathrm{MPa}$

\section{Final Platform}

As the original DeepCWind structure proved to be unable to cope with the applied stresses, a structural improvement was performed and is suggested here. This reinforcement consisted of using structural reinforcements, as well as adjusting the members' thicknesses. 
Structural Improvement

The first modification consisted on changing the way the UC and the $\mathrm{BC}$ are connected. On the original platform, the bottom of the $\mathrm{UC}$ is welded to the top of the $\mathrm{BC}$, as shown in the cut view on the left of Fig. 13. In order to strengthen both members, the UC was extended until the bottom of the $\mathrm{BC}$, being then welded there. This is shown in the cut view on the right of Fig. 13. Questioned
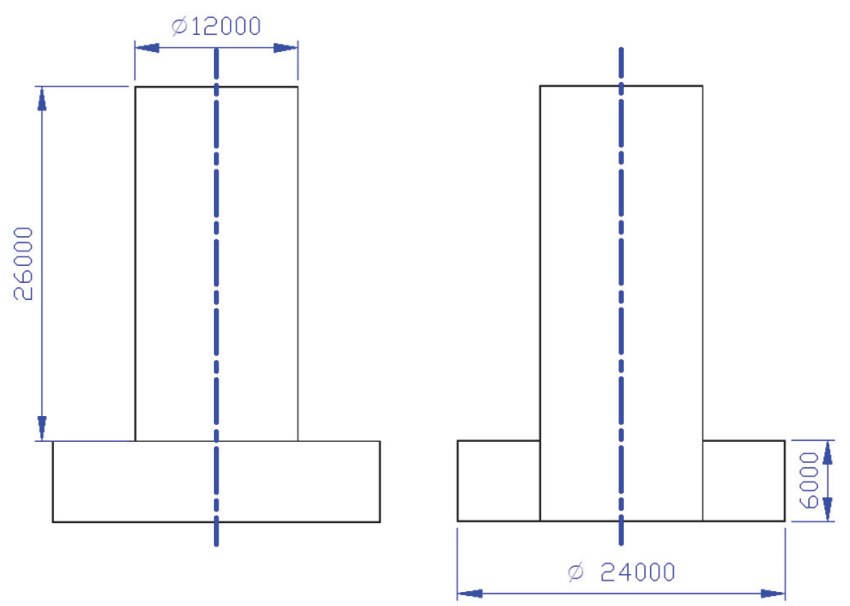

Figure 13: UC and BC joint cut view. Original on the left; Improved on the right.

As further strengthening was needed at the BC, structural reinforcements were used. Four types of reinforcements were considered:

- Sheetmetals of $5800 \mathrm{~mm}$ x $5890 \mathrm{~mm}$ with patterned holes, as shown in Fig. 14, which are assembled in a circular array around the UC, as shown in Fig. 15. The final design used 8 reinforcements of $60 \mathrm{~mm}$ in thickness;

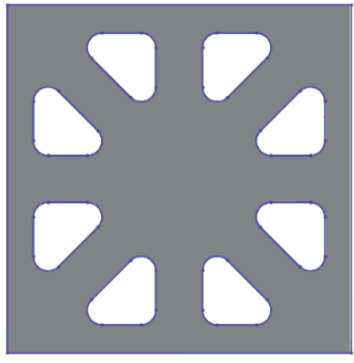

Figure 14: Reinforcement used at BC.

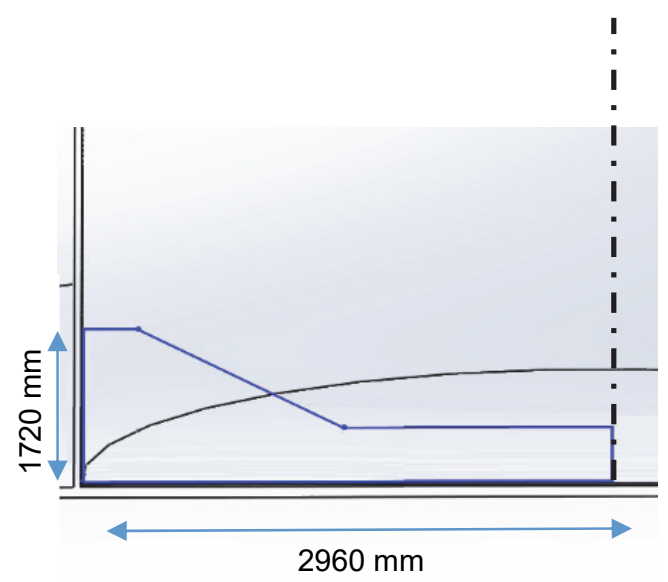

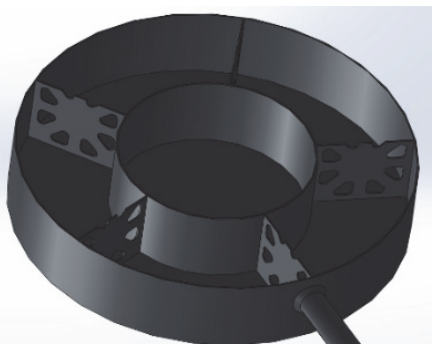

Figure 15: Reinforcements assembled.

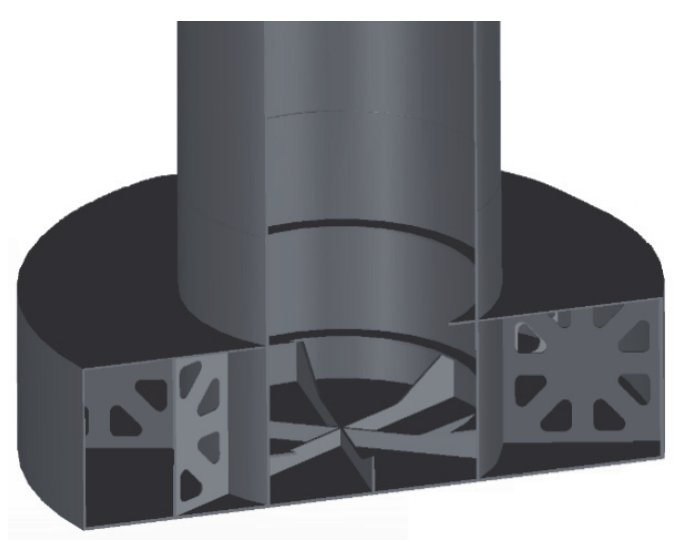

Figure 16 Central reinforcements at the BC. a) Dimensions; b) Location. 
- At the centre of the BC, reinforcements with the geometry show in Fig. 16 a) were used. These promoted the strengthening of the bottom of the $\mathrm{BC}$ without adding unnecessary weight. The reinforcements were assembled in a circular array around the centreline axis of the $\mathrm{BC}$ as shown in Fig. 16 b);

- Additionally, further reinforcements were used around the UC column. These are shown in Fig. 17. On the left, two symmetrical reinforcements are shown, being assembled one at the top of the $\mathrm{BC}$ and other at the bottom, both with $80 \mathrm{~mm}$ in thickness. The reinforcement on the right is installed only at the bottom. It possesses a similar geometry but having a thickness of $120 \mathrm{~mm}$ and being assembled perpendicularly to the previous ones.

The resulting assembled reinforcements are shown in Fig. 18. With the aim of decreasing the weight of the BC member, its thickness was segmented, meaning that the thicknesses are to remain high at zones of relatively large stresses, while being decreased at other regions of lower influence. The GL's guideline [13] states that for the alignment of plates of different thicknesses, the fiber of the medium plane should be used as reference. The misalignment of this fiber of both plates should not be higher than $3 \mathrm{~mm}$. Due to the high thicknesses involved in the present structure, it was decided not to use any misalignment of the fibers. The resulting segmented structure is shown in Fig. 19. The sheet metal used for the red zone has a thickness of $120 \mathrm{~mm}$ while for the green region, a thickness of $80 \mathrm{~mm}$ was used.

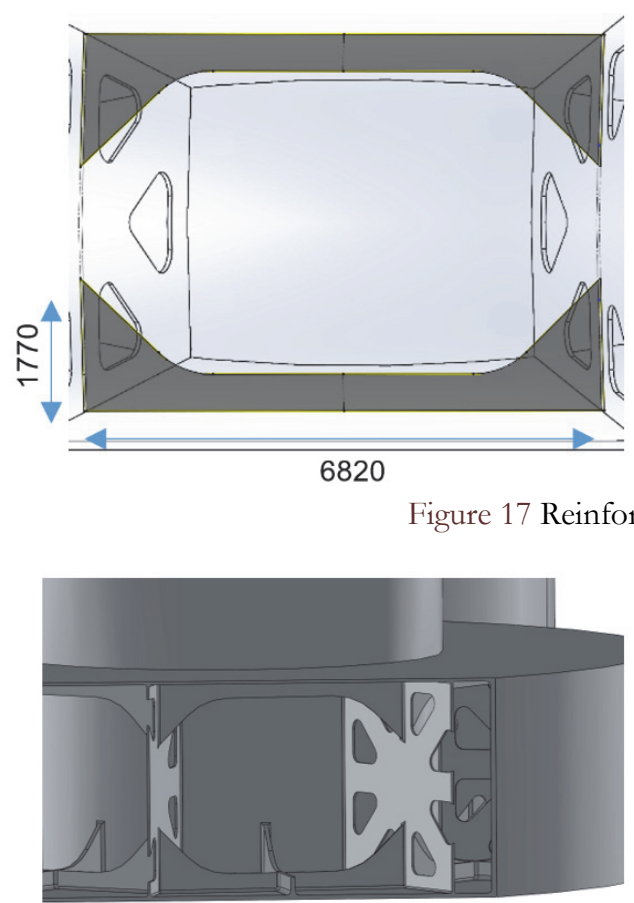

Figure 18 Reinforcements Layout.

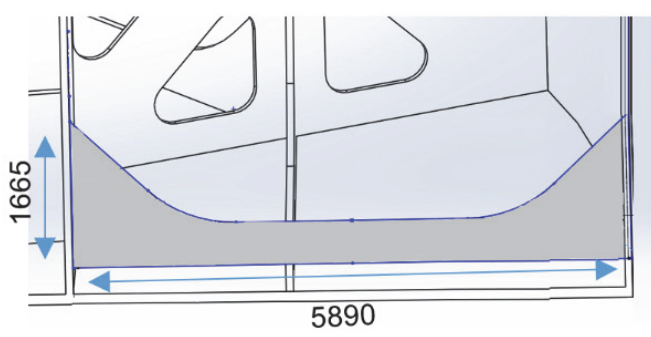

5890

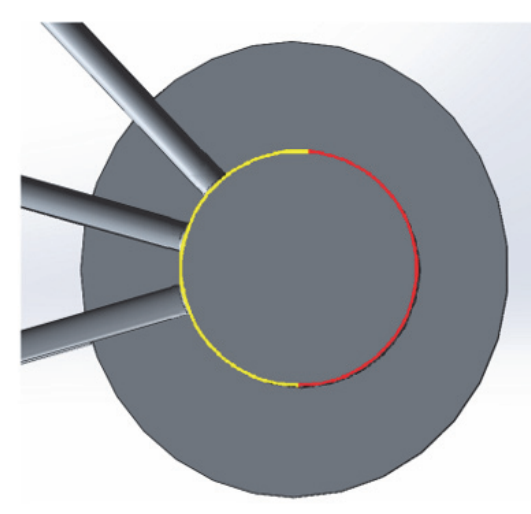

(a)

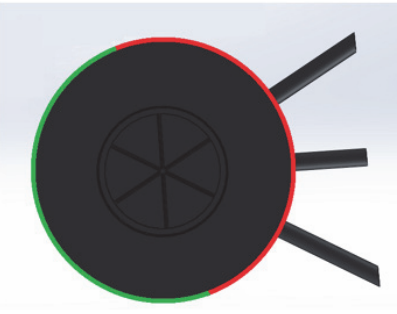

Figure 19 BC thickness segmentation.

Figure 20 UC. a) UC top view; b) UC side cut view. 
The UC reinforcement result is shown in Fig. 20. Thickness segmentations were also used. The green zone has $80 \mathrm{~mm}$ in thickness, whilst the red zone $60 \mathrm{~mm}$ and the yellow $140 \mathrm{~mm}$. Three circular reinforcements were used, as pointed by arrows in Fig. $20 \mathrm{~b}$ ). The top one is used to reinforce the horizontal transition from $140 \mathrm{~mm}$ to $60 \mathrm{~mm}$, the middle one is at the same level as the top of the $\mathrm{BC}$ and the bottom one is connected to the top of the radial reinforcements.

The MC member was also segmented. The red region possesses $180 \mathrm{~mm}$ in thickness while the green region has $90 \mathrm{~mm}$. At the bottom, reinforcements similar to those of the centre of the BC were used, being displayed in Fig. 21. In order to reinforce the connection areas, longitudinal and circular reinforcements were employed. At the top, the longitudinal and circular reinforcements have a thickness of $70 \mathrm{~mm}$ and $80 \mathrm{~mm}$, respectively. At the bottom, both the longitudinal and circular reinforcements have $100 \mathrm{~mm}$ in thickness. Additionally, at the thickness transition from $180 \mathrm{~mm}$ to $90 \mathrm{~mm}$, circular reinforcements were applied, as indicated by arrows in Fig. 22.

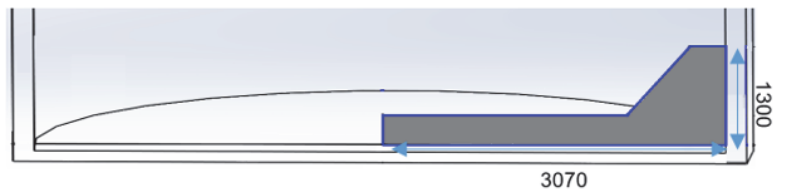

Figure $21 \mathrm{MC}$ 's bottom reinforcements. Geometry and Dimensions

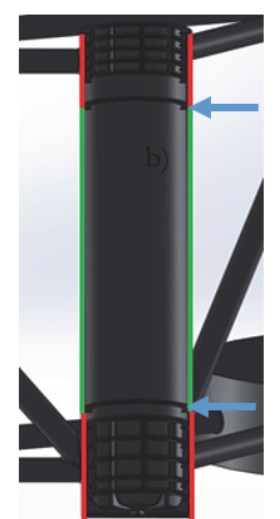

Figure 22 MC segmentation.

The joints of the Pontoons to the larger diameter members were emphasised as the areas of higher stresses in a previous project, which may be read in [18]. As such, minor layout alterations such as the use of conical transitions or the use of disjoint connections for the diagonal members were tried. After comparison of the results, no valuable advantage was evident. Therefore, the reinforcement of the Pontoons was achieved by thickness increment only. The improved foundation's pontoons now have thicknesses of: $100 \mathrm{~mm}$ for the DU and DL members, $150 \mathrm{~mm}$ for the CB and YU members and 160 for the YL member. Tab. 5 shows the comparison between the pontoons' original thicknesses and their improved thicknesses.

\begin{tabular}{ccc}
\hline Member Identification & $\begin{array}{c}\text { Original Wall } \\
\text { Thickness } \\
{[\mathrm{mm}]}\end{array}$ & $\begin{array}{c}\text { Final Wall Thickness } \\
{[\mathrm{mm}]}\end{array}$ \\
DU & 17.5 & 100 \\
DL & 17.5 & 100 \\
YU & 17.5 & 160 \\
YL & 17.5 & 150 \\
CB & 17.5 & 150 \\
\hline
\end{tabular}

Table 5 Comparison of the Original Pontoons' Thickness to Improved Pontoons’ Thickness.

\section{Final analysis}

The final analyses included transient analysis of 600 representative seconds at wind speeds of $11.4 \mathrm{~m} \mathrm{~s}^{-1}$ and of $24 \mathrm{~m} \mathrm{~s}^{-1}$. At both wind speeds, an analysis with the springs formulation and other with the displacements formulation as described in the Methods section. These analysis evaluated the von Mises stresses, with the aim of achieving safety coefficients above 1.2, as described on the reference standard [13]. 


\section{Modal Analysis}

On one hand, due to the reinforcement of the platform, its rigidity increased. On the other, the mass of the global structure is composed of the steel of the structure and of the water present inside the ballasts. The rise in the steel mass is compensated by a decrement in the mass of water, thus the structure's mass remains constant. Considering Eqn. 1, which is the formula used for the determination of the natural frequency of a simplified mass-spring system, as the stiffness increases, with the mass remaining constant, the natural frequencies will also increase.

$$
w_{n}=\sqrt{\frac{k}{m}}
$$

Fig. 23 shows the deformation shapes and Tab. 6 displays the values of the natural frequencies of interest for the final platform.

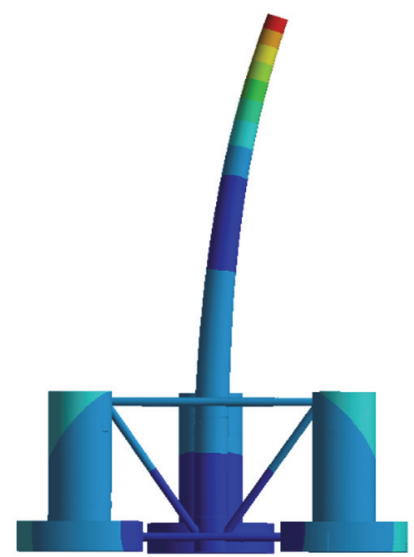

a)

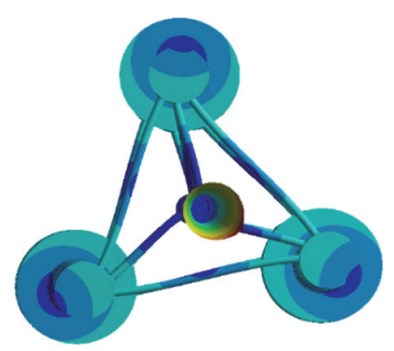

c)

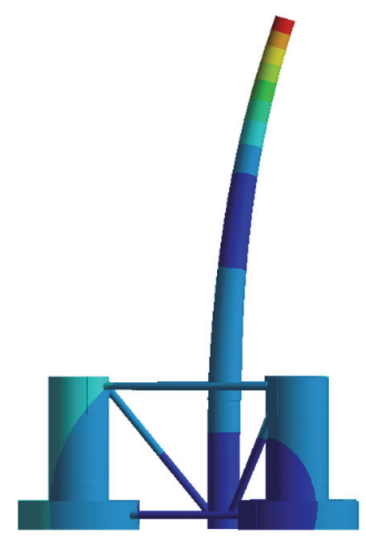

b)

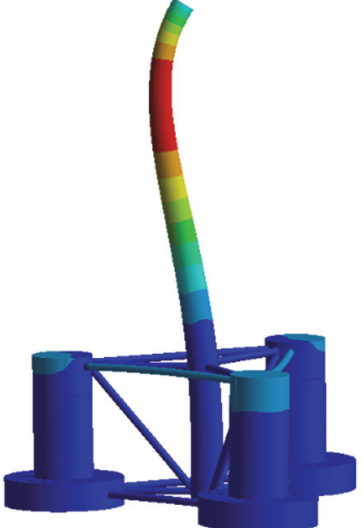

d)

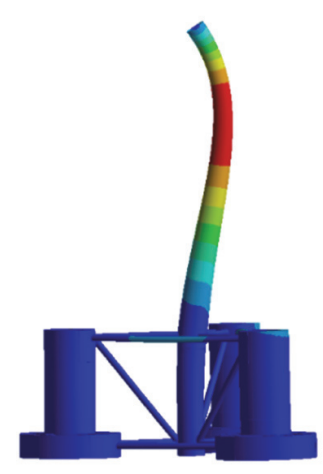

e)

Figure 23: Deformation Shapes from the Modal Analysis; a) Mode 1 - Side to Side; b) Mode 1 - Fore-Aft; c) Mode 2 - Torsion; d) Mode 2 - Fore-Aft; e) Mode 2 - Side-to-Side.

\begin{tabular}{ll}
\hline Mode Description & Frequency $[\mathrm{Hz}]$ \\
Mode 1 - Side-to-Side & 0.6896 \\
Mode 1 - Fore-Aft & 0.70212 \\
Mode 2 - Torsion & 1.8263 \\
Mode 2 - Side-to-Side & 2.1473 \\
Mode 2 - Fore-Aft & 2.5376 \\
\hline
\end{tabular}

Table 6: Mode description and respective frequency. 
Transient analysis at wind speeds of $11.4 \mathrm{~ms}^{-1}$

As early described, the springs formulation is used for the evaluation of the global model, whereas the displacements formulation is used for the examination of the BC member. Fig. 24 shows the global model results and Fig. 25 shows the BC's. Both figures display the results of the respective models at the time of highest stresses verified during the 600 seconds evaluation.

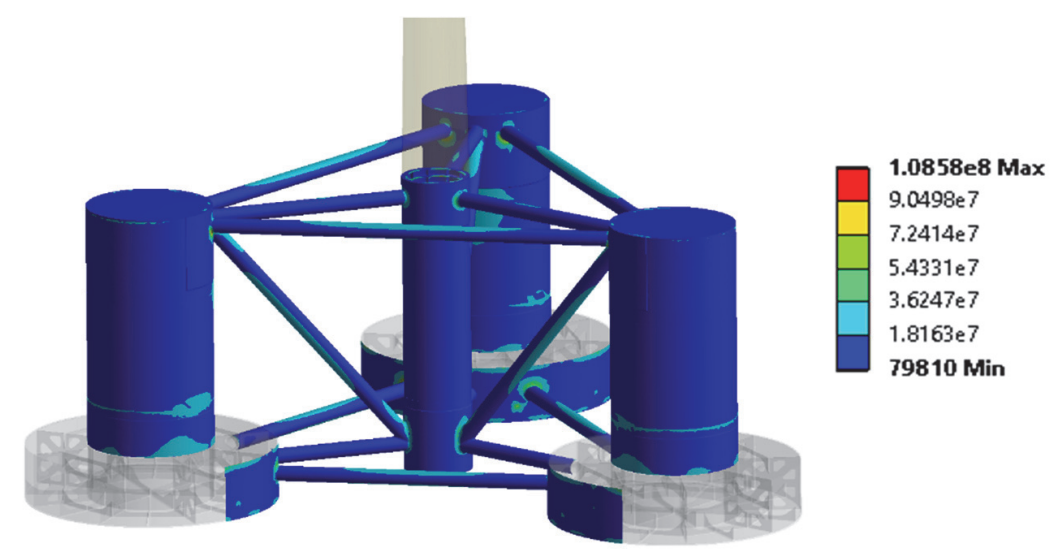

Figure 24: Global model analysis with springs formulation. Units in Pascal.

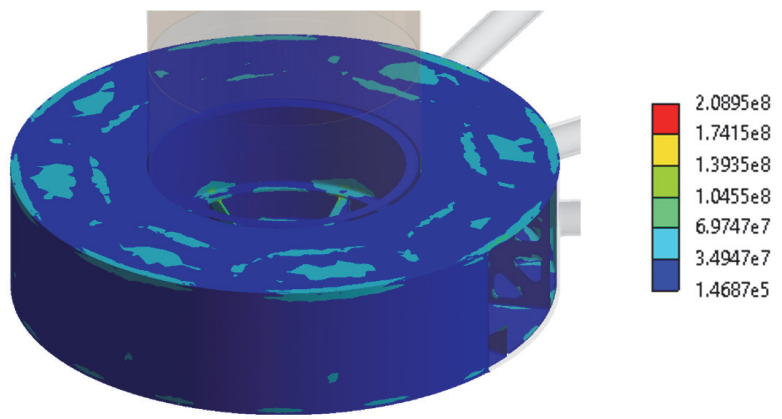

Figure 25: BC analysis with the displacements formulation. Units in Pascal.

The global model reveals that structural reinforcements allowed achieving a minimum safety coefficient of 3.22, with a maximum stress of $109 \mathrm{MPa}$. The BC examination reveals a maximum stress of $209 \mathrm{MPa}$. Although it establishes a safety coefficient of 1.67, thus being above the desired coefficient, the presence of singularities may be reducing the safety coefficient. Future examinations should consider these locations carefully.

For the sake of comparison, some points were chosen from the springs formulation to be compared with the analysis of the original foundation with the same formulation, at $11.4 \mathrm{~m} \mathrm{~s}^{-1}$. Fig. 26 shows the location of these points. Tab. 7 shows the values of stress at these locations, as well as the magnitude at the same point for the original foundation.
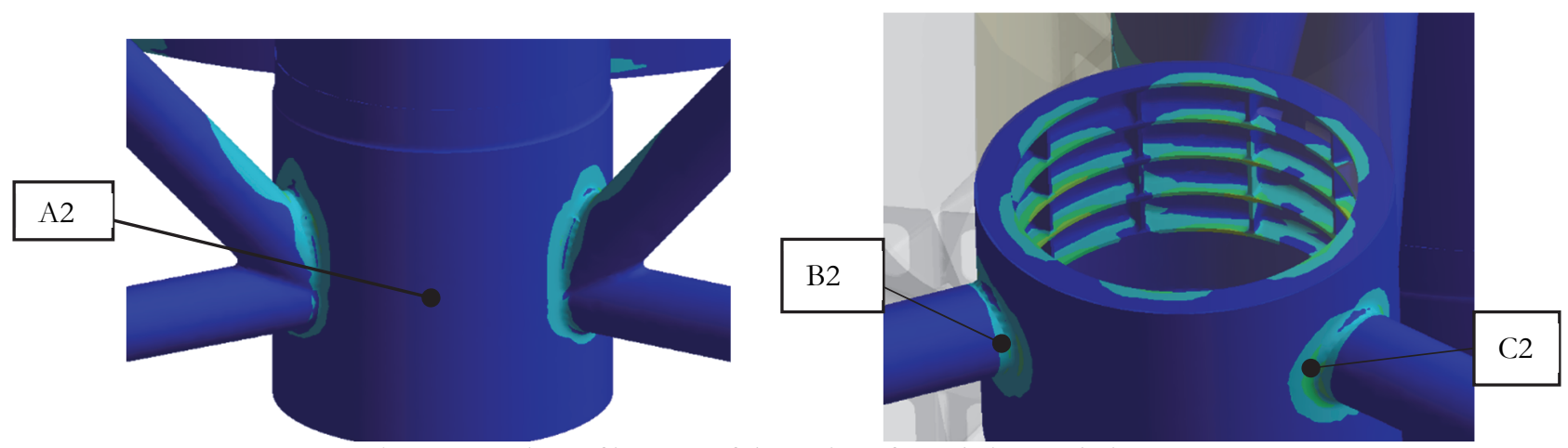

Figure 26: Points of interest of the springs formulation analysis. 


\begin{tabular}{lcll}
\hline \multicolumn{2}{l}{ Original Foundation } & \multicolumn{2}{l}{ Reinforced Foundation } \\
Point & Stress Value & Point & Stress Value \\
V1 & $376.87 \mathrm{MPa}$ & A2 & $21 \mathrm{MPa}$ \\
L1 & $294 \mathrm{MPa}$ & B2 & $29 \mathrm{MPa}$ \\
N1 & $336.7 \mathrm{MPa}$ & C2 & $32 \mathrm{MPa}$ \\
\hline
\end{tabular}

Table 7: Comparison of results between points of interest of the original foundation analysis and the reinforced foundation analysis, both using the springs formulation at $11.4 \mathrm{~m} \mathrm{~s}^{-1}$.

\section{Transient analysis at wind speeds of $24 \mathrm{~ms}^{-1}$}

Fig. 27 shows the global model analysis at wind speeds of $24 \mathrm{~m} \mathrm{~s}^{-1}$ and Fig. 28 shows the results of the BC analysis at the same speed. The highest stress for the springs formulation is $113 \mathrm{MPa}$, yielding a safety coefficient of 3.11 . For the displacements formulation, the highest stress verified is $210 \mathrm{MPa}$, achieving a safety coefficient of 1.668. Once again, the influence of singularities should be carefully analysed in future works.

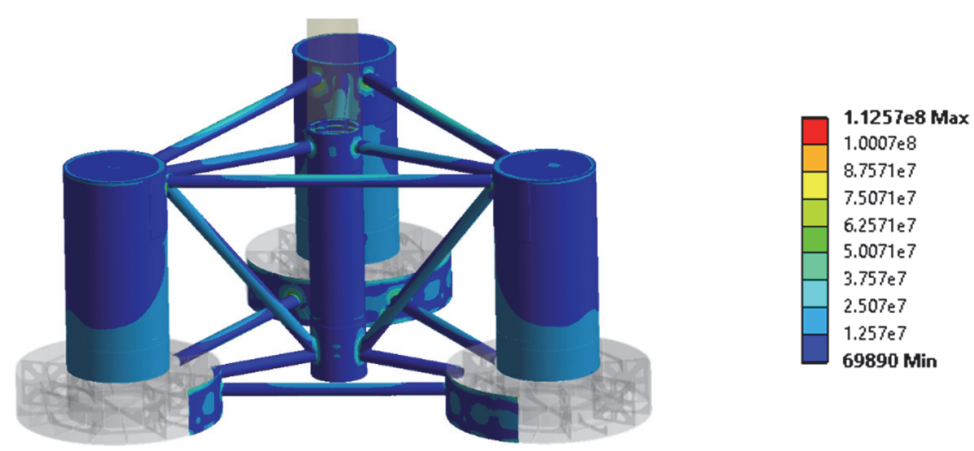

Figure 27: Global model analysis with springs formulation. Units in Pascal.

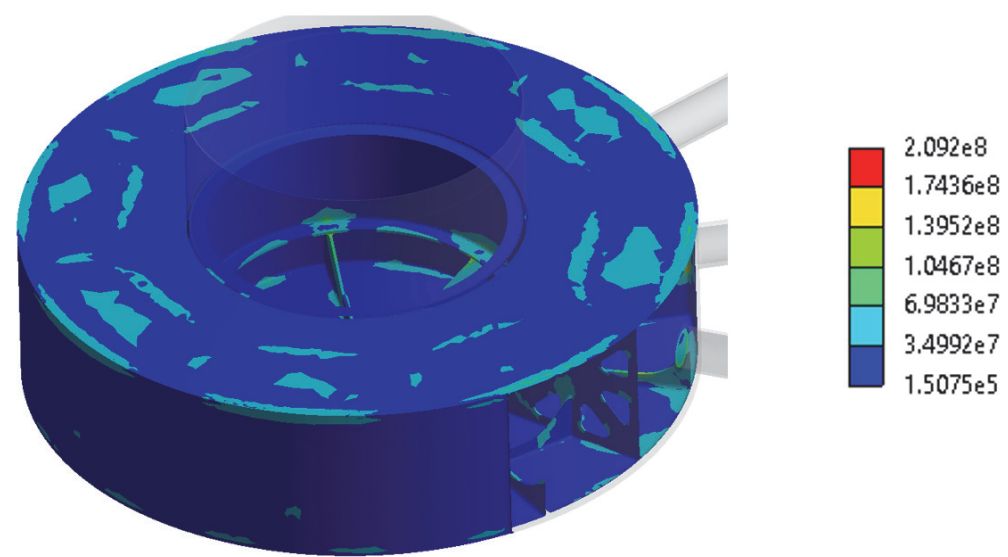

Figure 28: BC analysis with the displacements formulation. Units in Pascal.

\begin{tabular}{ccc}
\hline Properties & Original Structure & Final Structure \\
Steel Mass [Tonnes] & 3852 & 9543 \\
Overall Ballast's Water Mass [Tonnes] & 9621 & 3930 \\
Fundamental Frequency [Hz] & 0.278 & 0.6896 \\
Lower Safety Coefficient at $11.4 \mathrm{~m} \mathrm{~s}^{-1}$ & 0.032 & 1.67 \\
Lower Safety Coefficient at $24 \mathrm{~m} \mathrm{~s}^{-1}$ & $\begin{array}{c}\text { Analysis not } \\
\text { performed }\end{array}$ & 1.668 \\
\hline
\end{tabular}

Table 8: Mode description and respective frequency. 
Comparison of Results

Tab. 8 shows a comparison of some key aspects between the results of the original foundation and the improved foundation.

\section{CONCLUSIONS}

I $\mathrm{n}$ this research, the structural analysis of the DeepCWind platform was produced. For the original platform, the modal analysis gives suitable results as it is shown that the structure fundamental frequency, as well as others of the most damaging frequencies, do not coincide with the frequencies of excitation that are most probable to occur and that were of concern for the design load case assessed. When it comes to the static analyses, the results are unsatisfactory, with both of formulations used yielding results over the elastic limit, considering the Von Mises criteria. The considered yield strength of the steel is $355 \mathrm{MPa}$ but the elastic FEM analysis registered stress values above $10000 \mathrm{MPa}$. This makes a difference larger than twenty-five times the minimum required (without even considering the factor of safety from the respective standards).

In addition, the mean wind speed considered was $11.4 \mathrm{~m} \mathrm{~s}^{-1}$; to satisfy the requirements of the considered DLC, it should endure wind mean speeds of $25 \mathrm{~m} \mathrm{~s}^{-1}$ in transient analysis. Moreover, the platform should be robust enough to withstand critical situations, such as storms, which are examined in other Design Loading Cases.

Due to the unsatisfactory results, the DeepCWind platform required structural improvements.

The results of the analyses of the structurally improved DeepCWind platform revealed pleasing results, yielding security coefficients above the required by the respective standards. Further tests should be performed, such as fatigue and damage accumulation evaluations. All the DLC should be conducted for the acceptance of a structure for practical implementation. In conclusion, the DeepCWind original platform is shown to be unable to support the loads and excitations that it was conceptually designed for. The insufficient thicknesses as well as the lack of structural reinforcements explain these results. The present reinforced structure shows potential for implementation. However, the existence of the MC member in the DeepCWind platform is a great disadvantage when compared to other platforms such as the WindFloat. The WindFloat's tower is positioned on top of one of the larger diameter member, allowing for the removal of central column and respective connection members. This layout alteration may bring great advantages.

It must be noted that the DeepCWind Consortium did not partake on the development of the structure from a mechanical design perspective; instead, its intended use was focused on the validation of hydrodynamic models. As such, this paper credits no responsibility to them regarding the conclusions on structural integrity.

\section{ACKNOWLEDGEMENTS} he authors acknowledge support for this research from the MIT Portugal Program Scholarship
PD/BD/114146/2016. The authors also thank the support of FCT, through IDMEC, under LAETA project
UID/EMS/50022/2019.

\section{REFERENCES}

[1] International Energy Agency (2018), World Energy Outlook 2018 - Executive Summary.

[2] UNFCC, (2015) Adoption of the Paris Agreement.

[3] Vieira, M., Snyder, B., Henriques, E., Reis, L. (2019). European o ff shore wind capital cost trends up to 2020, Energy Policy, 129, pp. 1364-1371.

[4] Vieira, M., Henriques, E., Amaral, M., Arantes-Oliveira, N., Reis, L. (2018). Path discussion for offshore wind in Portugal up to 2030, Mar. Policy, pp. 1-10.

[5] Wind Europe, Offshore Wind in Europe: Key trends and statistics 2018, (2019).

[6] Carbon Trust, Offshore wind power: big challenge, big opportunity, (2008).

[7] Alessi, L., Correia, J. A. F. O., Fantuzzi, N. (2019). Initial design phase and tender designs of a jacket structure converted into a retrofitted offshore wind turbine, Energies, 12(4).

[8] Todd, J., Chen, J., Clogston, F. (2013). Creating the Clean Energy Economy: Analysis of the Offshore Wind Energy Industry.

[9] Robertson, A. et al., (2013). Summary Of Conclusions And Recommendations Drawn From The Deepcwind Scaled 
Floating Offshore Wind System Test Campaign, Proc. ASME 2013 32nd Int. Conf. Ocean. Offshore Arct. Eng., pp. $1-13$.

[10] Robertson, A. et al., (2014). Definition of the Semisubmersible Floating System for Phase II of OC4.

[11]Jonkman, J., Butterfield, S., Musial, W., Scott, G., (2009). Definition of a 5-MW Reference Wind Turbine for Offshore System Development.

[12] Nikishkov, G. P. (2004). Introduction to the Finite Element Method, University of Aizu.

[13] Germanischer Lloyd (2012). Guideline for the Certification of Offshore Wind Turbines.

[14] Mourão, A. et al. (2019). Fatigue Damage Analysis of Offshore Structures using Hot-Spot Stress and Notch Strain Approaches, Exp. Mech. Solids Mater. Res. Forum LLC Mater. Res. Proc., 12, pp. 146-154.

[15] Maciel, G. da S. G., (2016), Desenvolvimento e Projeto Mecânico de uma Fundação para uma Turbina Eólica Offshore Engenharia Mecânica.

[16] Jonkman, J. M., Buhl, M. L. (2005). FAST User's Guide.

[17]Jonkman, J. M., Robertson, A. N., Hayman, G. J., HydroDyn User's Guide and Theory Manual.

[18] Dias, D. R., (2017). Análise da Integridade Estrutural duma Fundação Flutuante para Energia Eólica Offshore Engenharia Mecânica.

[19] Lee, H.-H. (2017). Finite Element Simulations with ANSYS Workbench 17. Stephen Schroff.

[20] DNV/Riso, (2002). Guidelines for Design of Wind Turbines.

[21] Letcher, T. M., (2017). Wind Energy Engineering: A handbook for onshore and offshore wind turbines.

[22] Ansys 2019R1 Help Section, Static Structural Analysis. .

[23] Akin, J. E., (2019). Finite Element Analysis Concepts via SolidWorks.

[24] Adams, V., Askenazi, A., (1998). Building Better Products with Finite Element Analysis, 1st ed. OnWord Press.

[25] Ansys 2019R1 Help Section, Skewness. .

[26] Olivera, G. A., Structural Dynamic Behaviour of a Floating Platform for offshore Wind Turbines.

[27] Hordvik, T. (2011). Design analysis and optimisation of mooring system for floating wind turbines Student: Open Floating wind turbine Mooring system Optimisation, Norwegian University of Science and Technology.

[28] Cruz, J., Atcheson, M., Collu, M.,(2016). Floating Offshore Wind Energy - The Next Generation of Wind Energy.

[29] Ansys 2019R1 Help Section, Point Mass. .

[30] ANSYS, FEA Best Practices. 